\title{
47
}

\section{Machines, Pieces of Paper and Rubber Bands}

Fifteen years ago, management bought used machines and these have never functioned properly. When workers are hired, they have to sign a document saying that if they break the house rules, they will be dismissed. One of the rules is that they always have to call in the maintenance department if a problem arises with a machine. In spite of that, they take care of the constantly jammed machines themselves as they do not think that the maintenance department is competent enough to do so. One of them said: 'Maintenance don't know shit about this machine. You gotta be able to fix it. Sure they know how to replace something but they really don't know how it works.' The machines have to run properly if the flow of work is to be maintained.

Since the workers are breaching the rules whenever they repair the machines, they have to conceal what they do from management. The result is that they do not have access to the tools and materials necessary to do this work, instead having to use whatever they can get their hands on: pieces of paper and rubber bands, for example.

(Martin, 1986) 